\title{
Stress relaxation behavior of wood in the plastic region under indoor conditions
}

\author{
Yoshiaki Wakashima ${ }^{1 *} \mathbb{D}$, Hidemaru Shimizu², Akihisa Kitamori ${ }^{3}$, Doppo Matsubara ${ }^{4}$, Koichiro Ishikawa ${ }^{5}$ \\ and Yasushi Fujisawa'
}

\begin{abstract}
The stress relaxation behavior of wood in the plastic region was measured by clamping wood specimens with bolts for up to 5 years under indoor environmental conditions. An initial stress was applied by displacement control, whereby a steel plate or a washer was embedded in the radial direction of the wood. The difference in the stress ratio was small in the plastic region due to the difference in the initial stress level, and the higher the initial stress, the higher the stress that was maintained. By contrast, the clamp force virtually disappeared in the elastic region. The estimated stress ratio after 50 years was $15 \%$ in the elastic region and approximately $20-40 \%$ in the plastic region. Due to the influence of humidity fluctuation, it was difficult to maintain stress in the elastic region, but it seems to be possible to maintain the stress for a long time using partial plastic embedment with sufficient extra end distance.
\end{abstract}

Keywords: Stress relaxation, Connections, Clamp force, Long-term prediction

\section{Introduction}

Joints with dowel-type fasteners are the most common shear joints in timber structures. When the design forces are relatively large, bolt connectors are typically used instead of nails. In spite of their high load-carrying capacity, bolt connections are characterized by a low stiffness at initial loading due to the effects associated with oversized lead holes because, unlike high tension bolts in steel structures, a significant frictional force generated by the tightening of the bolts is not expected due to the stress relaxation properties of wood. Consequently, according to the standard for structural design of timber structures [1], the initial clamping conditions for bolts are described such that the washer is slightly embedded in the wood, and no clear provision is given. However, in the destructive testing of bolted joints with an axial force applied at several levels using a torque wrench, high stiffness and strength values due to friction have been reported [2]. This indicates that the influence of the friction from the initial clamp force of the bolt is relatively large.

\footnotetext{
*Correspondence: yoshiaki.wakashima@pref.toyama.lg.jp

${ }^{1}$ Toyama Prefectural Agricultural Forestry \& Fisheries Research Center, 4940, Imizu, Toyama 939-0311, Japan

Full list of author information is available at the end of the article
}

Awaludin et al. [3] examined the effect of the pretension force applied to the bolts used in moment-resisting joints and reported an increase in the initial rotational stiffness and hysteretic dumping in those joints. However, they also suggested that the initial prestressing effect must be considered negligible based on the results of the 1-year stress relaxation tests without restressing [4].

We are also developing a high damping shear wall, in which the clamp force of bolts in the wood acts as frictional resistance between two timber members or between a timber member and a steel plate [5-7]. The relaxation behavior of the clamp force and controlling the clamp force are both considered in this study. When clamping is applied in the elastic region, the tightening torque method would generally be applicable $[8,9]$; however, it has been reported that the stress tends to disappear in that region $[4,10]$. Thus, we applied a form of displacement control by embedding a washer in the wood to control the clamp force. To obtain a stable frictional force for a long period of time using the method, it is necessary to examine long-term stress relaxation behavior in the plastic region of wood.

While the rheological behavior of wood, such as stress relaxation and creep, has been studied extensively $[11,12]$, in a report on stress relaxation of clamp 
force associated with bolts or bars in the elastic region, for example, the study related to a stress-laminated timber bridge is described. Extrapolating the results of wood that was tensioned three times in the first 50 days, it was predicted that the stress ratio after 50 years would be $84 \%$ [13], though as the authors also noted, the results used for extrapolation were obtained after only 100 days of observation, and did not take long-term losses due to temperature change or decreases in moisture content into account. Hislop [14] reported that bar tension force decreased by $67 \%$ during a 3 -year monitoring period due to the large decrease in moisture content as well as wood stress relaxation. At the end of the monitoring, the bars were restressed, and during the subsequent 3 years, the force decreased by $50 \%$. Ritter et al. [15] recommended that stress-laminated bridges be stressed three separate times over a period of $6-8$ weeks. For construction with sawn lumber, they also indicated that the bar force should be checked annually for the first 2 years after construction and every 2 years thereafter. Thus, restressing and regular bolt maintenance are necessary to maintain the axial force; however, it is unrealistic to periodically check the bolts inside the walls of wooden houses.

The clamp force in a stress-laminated bridge is considered to be the elastic region. Fujimoto et al. [16] conducted stress relaxation tests in the plastic region by embedding a washer in spruce wood using bolts and reported that relaxation developed as the clamp force increases. Manrique [17] also reported similar behavior in the compression of tropical wood. However, these results were obtained from a stress relaxation test from $8 \mathrm{~h}$ to 1 week, in which the test period was too short to estimate the long-term performance.

In this study, under the premise that restressing is not performed, the stress relaxation behavior of wood in the plastic region was measured over a relatively long period of time. Practically, the tests were conducted in an indoor environment with temperature and humidity fluctuations, which are more unfavorable for the relaxation of wood than maintaining constant temperature and humidity $[11,12]$, and the influence of high stress, test period, and humidity was examined. Long-term predictions of the stress retention of wood are also presented.

\section{Materials and methods}

Stress relaxation tests of wood subjected to a transverse compressive force were conducted. The tests were divided into four series and details of the testing configurations of each series are shown in Fig. 1. Series A shown in Fig. 1a is a method of embedding a steel plate into wood by tightening bolts and assuming a connection with an extra area of wood on all four sides of the plate. Sufficient extra end distance was employed

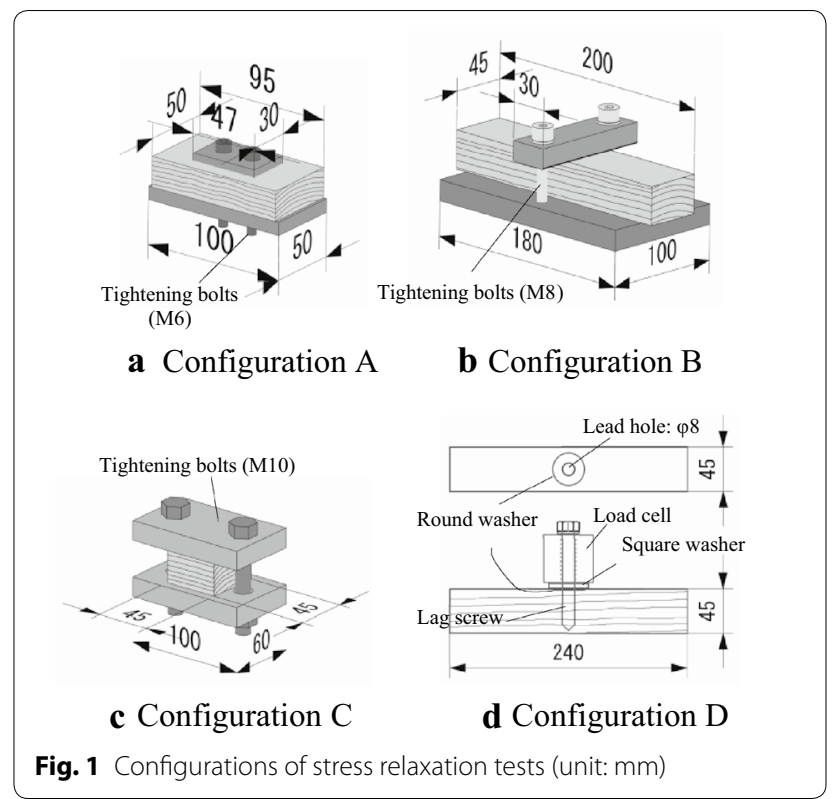

for both sides of the embedded steel plate in series $B$, as shown in Fig. 1b. The corners of the wood contact surface of both the steel plates of series A and B are slightly chamfered. To evaluate the influence of the support area, a full surface compression test (series C, Fig. 1c) was also performed by sandwiching the wood with steel plates. Series D shown in Fig. 1d is a partial compression test in which a washer was embedded in wood using the pull-out reaction force of a lag screw. For series $B$ and $C$, the ends of the specimens were waterproofed by paraffin.

Wood samples were obtained from sugi (Cryptomeria japonica) lumber and materials used in series $\mathrm{A}$ were cut from the same lumber. The specimens were stored at a temperature of $20{ }^{\circ} \mathrm{C}$ and a relative humidity of $60 \%$ for a week or more before the test. Table 1 summarizes basic properties of the specimens and the features of the tests.

The initial stress of each specimen was given by the transverse compressive displacement, as shown in Table 1. The displacement applied to series A and B was controlled by the rotation angle of the nut according to the pitch of the bolt. For 30-PE and 30-FE specimens, the initial stress level was set sufficiently below the resistance value of sugi in compression perpendicular to the grain to evaluate the behavior within the elastic region. Because the proportional limit was about $3 \mathrm{MPa}$ for full compression and 3.3 MPa for partial compression from the static compression test of the end-matched specimens, the initial conditions for 30-PE and 30-FE shown in Table 1 are considered to be within the elastic region.

The bolts and the lag screw were tightened manually with a wrench, in which case the tightening period 
Table 1 Basic properties of materials and testing conditions

\begin{tabular}{|c|c|c|c|c|c|c|c|c|}
\hline $\begin{array}{l}\text { Designation } \\
\text { of specimens }\end{array}$ & Dimension $(\mathrm{mm})$ & $\begin{array}{l}\text { Density } \\
\left(\mathrm{kg} / \mathrm{m}^{3}\right)\end{array}$ & MC (\%) & Paraffin & Embedment size $(\mathrm{mm})$ & Initial condition & Sensor & Delay days \\
\hline \multicolumn{9}{|l|}{ A } \\
\hline $20-P 0.5$ & $95 \times 20 \times 50$ & 318 & 13.2 & - & $47 \times 30$ & $0.5 \mathrm{~mm}$ & SG & 0 \\
\hline 20-P1 & $95 \times 20 \times 50$ & 321 & 12.7 & - & $47 \times 30$ & $1 \mathrm{~mm}$ & SG & 0 \\
\hline $20-P 2$ & $95 \times 20 \times 50$ & 325 & $12.9^{\mathrm{a}}$ & - & $47 \times 30$ & $2 \mathrm{~mm}$ & SG & 0 \\
\hline \multicolumn{9}{|l|}{ B } \\
\hline 30-P1.5 & $200 \times 30 \times 45$ & 358 & $9.5^{\mathrm{b}}$ & O & $30 \times 45$ & $1.5 \mathrm{~mm}$ & SG & 650 \\
\hline $45-\mathrm{P} 1.5$ & $200 \times 45 \times 45$ & 354 & $9.8^{\mathrm{b}}$ & 0 & $30 \times 45$ & $1.5 \mathrm{~mm}$ & SG & 650 \\
\hline 30-PE & $200 \times 30 \times 45$ & 358 & $9.5^{b}$ & 0 & $30 \times 45$ & $2.2 \mathrm{MPa}$ & SG & 650 \\
\hline 30-P1.6A & $200 \times 30 \times 45$ & 470 & $11.5^{b}$ & 0 & $30 \times 45$ & $1.6 \mathrm{~mm}$ & SG & 869 \\
\hline 30-P1.6B & $200 \times 30 \times 45$ & 421 & $11.7^{\mathrm{b}}$ & O & $30 \times 45$ & $1.6 \mathrm{~mm}$ & SG & 870 \\
\hline 90-P1.6 & $200 \times 90 \times 45$ & 403 & $12.4^{b}$ & 0 & $30 \times 45$ & $1.6 \mathrm{~mm}$ & SG & 870 \\
\hline \multicolumn{9}{|l|}{ C } \\
\hline 30-FE & $45 \times 30 \times 45$ & 344 & $9.5^{b}$ & O & $45 \times 45$ & $0.8 \mathrm{MPa}$ & SG & 636 \\
\hline \multicolumn{9}{|l|}{ D } \\
\hline L45-P2.3 & $240 \times 45 \times 45$ & 329 & $9.7^{\mathrm{b}}$ & - & $\begin{array}{l}\text { Round washer } \\
\text { OD: } 32 \text {, ID: 13.5, T: } 2.3\end{array}$ & $2.3 \mathrm{~mm}$ & LC & 307 \\
\hline
\end{tabular}

MC, moisture content; SG, strain gage; LC, load cell; OD, outside diameter; ID, inside diameter; $T$, thickness

a Average value of 20-P0.5 and 20-P1

b Obtained from the end-matched specimen, Paraffin: End of specimen is waterproofed by paraffin

was not constant. Considering the stress relaxation that occurs during tightening, it is necessary to keep the torque imposition time constant [18]. Since the relaxation test periods are sufficiently long with respect to the torque imposition time, and it is difficult to keep the tightening time constant in actual construction conditions, the imposition time was not considered in this study.

The clamp force was monitored by strain gages attached to the bolt, and the influence of temperature changes was corrected with dummy gages. The axial force of the lag screw was monitored by a load cell. The test data were recorded at intervals of $1 \mathrm{~s}$ when tightening the specimen, and thereafter it was recorded at 30-min intervals. The test start dates were different, as shown in Table 1, and the maximum interval was 870 days among the tests. The specimens were placed in an indoor environment where the temperature and humidity were not constantly controlled, but the room was heated occasionally during the day during winter months.

\section{Results and discussion}

\section{Effect of embedded displacement}

The stresses calculated by dividing the clamp force by the area of the embedded steel plate for the first 113 days obtained from series A are shown in Fig. 2 with the temperature and relative humidity of the surroundings. Table 2 shows the maximum initial clamp forces on each specimen. 20-P0.5 and 20-P1 display virtually the same

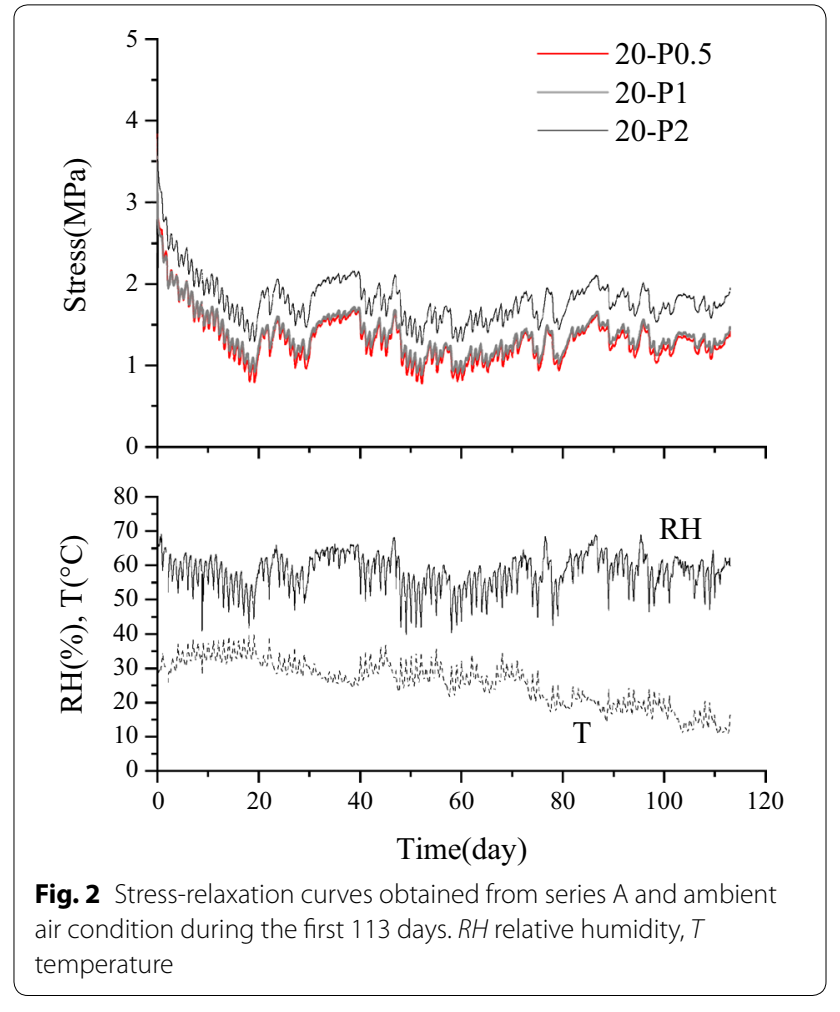

initial stress, both of which are considered to reach the plastic region of wood because the proportional limit was about $3 \mathrm{MPa}$ from the static compression test, owing to 
Table 2 Observed initial stress

\begin{tabular}{|c|c|c|c|}
\hline $\begin{array}{l}\text { Designation } \\
\text { of specimens }\end{array}$ & Init (MPa) & $1 \mathrm{~min}(\mathrm{MPa})$ & $1 \mathrm{~min} /$ init \\
\hline 20-P0.5 & 3.83 & 3.47 & 0.91 \\
\hline 20-P1 & 3.86 & 3.40 & 0.88 \\
\hline 20-P2 & 5.00 & 4.45 & 0.89 \\
\hline 30-P1.5 & 5.14 & 4.56 & 0.89 \\
\hline $45-P 1.5$ & 5.17 & 4.42 & 0.85 \\
\hline 30-PE & 2.20 & 2.11 & 0.96 \\
\hline 30-P1.6A & 6.14 & 4.87 & 0.79 \\
\hline 30-P1.6B & 7.53 & 6.09 & 0.81 \\
\hline 90-P1.6 & 8.02 & 6.93 & 0.86 \\
\hline 30-FE & 0.88 & 0.80 & 0.91 \\
\hline Lag45-P2.3 & 6.41 & 5.66 & 0.88 \\
\hline
\end{tabular}

Init, initial stress; 1 min, stress 1 min after tightening

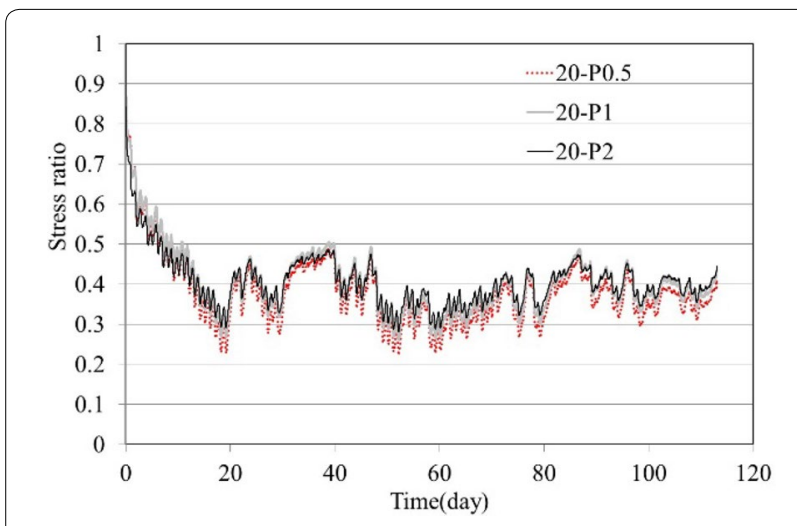

Fig. 3 Stress ratio curves obtained from series A

the configuration A performed on the end-matched specimen. However, 20-P2 maintained a higher stress than other specimens (Fig. 2), but the overall observations indicated the stress followed the same pattern as the other specimens. After rapid stress relaxation for the first 20 days, the stress of each specimen was relatively stable under the influence of relative humidity. The humidity of the surroundings continued to decrease for about 20 days from the start of the test, thus, indicating that the initial rapid stress reduction was influenced by the change in humidity.

Since the speed of data acquisition while tightening was relatively slow and the tightening speed was also indefinite due to manual fastening, the maximum clamp force could not be recorded. Therefore, the clamp stress was normalized as the stress ratio by the $\sigma_{1 \mathrm{~min}}$ which is the clamp stress $1 \mathrm{~min}$ after tightening is completed. Figure 3 shows the stress ratios obtained from series A. Although 20-P0.5 showed a slightly lower tendency, each specimen showed virtually the same stress ratios over the experimental observation period, and the difference in the stress ratio due to the difference in the initial displacement was not clearly observed. Thus, a high initial stress is considered to maintain a high clamp force.

Many previous studies have indicated that wood can be treated as a linear viscoelastic material within certain limits of stress, but at higher levels it became nonlinear $[11,12]$. On the other hand, Manrique [17] reported that stress relaxation of wood is not a linear stress function at any stress level.

Kuwamura [18] suggested that the judgment of linearity of wood is unclear in previously conducted research due to differences in the imposed time needed to reach the target load or strain, merging creep strain at supports, and individual difference between specimens. He carried out the experimental tests excluding the above pitfalls and concluded that the viscoelastic behavior of wood is nonlinear even at a low stress level. However, in the case of restressing wood in its plastic region, the behavior was reported to be close to linear [19]. It is important to note that Fig. 3 was generated from the results without restressing, which showed virtually the same curves, regardless of the difference in stress level mentioned above. From Fig. 7 in that report [19], the viscoelastic behavior without restressing was close to linear within the plastic region, where the embedded displacement exceeded $0.2 \mathrm{~mm}$ in radial load on the late wood surface. Therefore, the effect of imposition time can be neglected over the long term, and the behavior of the wood appeared to be relatively close to linear viscoelastic, regardless of embedded displacement in the plastic region.

\section{Effect of clamping in the plastic region}

Figure 4 illustrates the stresses obtained for 30-P1.5, 30-PE and 30-FE as a function of time. The stress $\sigma_{1 \mathrm{~min}}$ of 30-PE was as low as the allowable stress level of sugi in partial compression perpendicular to the grain, as shown in Table 2, and over time, the stress was lower than that of 30-P1.5. Translating the stress of 30-PE at about $1 \mathrm{MPa}$ on the vertical axis, however, over time, the stress became virtually the same after 90 days. The stress $\sigma_{1 \mathrm{~min}}$ of 30-FE was $0.8 \mathrm{MPa}$, which is the same as the allowable stress of the full transverse compression of sugi, and the stress decreases to zero after 30 days from the start of the test.

Figure 5 shows the stress ratio $\sigma(t) / \sigma_{1}$ min of each specimen. Although $\sigma_{1 \mathrm{~min}}$ of 30-PE was less than half that of 30-P1.5, the fluctuation of stress after 90 days was similar, which resulted in an emphasis on the fluctuation of the stress ratio. The stress ratio of 30-PE virtually disappeared (i.e., decrease to about $3 \%$ ) at around 300 days. Thus, it is difficult to conclude that a clamp 


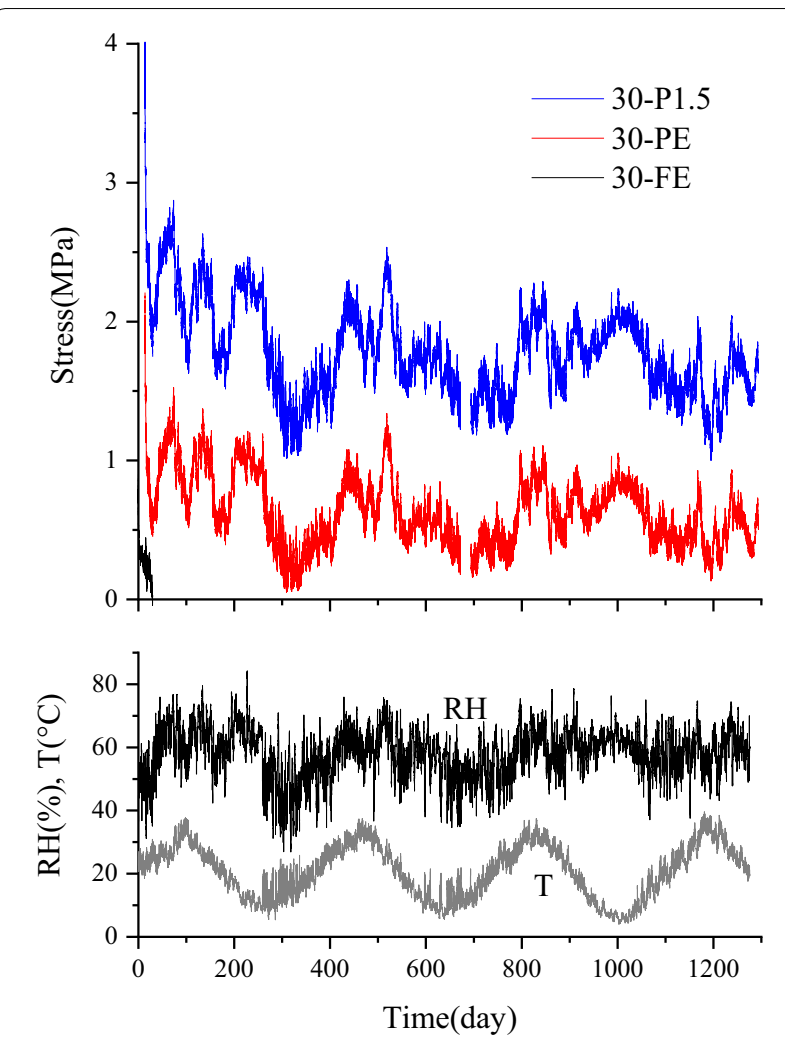

Fig. 4 Comparison of the stress relaxation curves in the different initial stress levels and ambient air condition during the tests. $\mathrm{RH}$ relative humidity, $T$ temperature

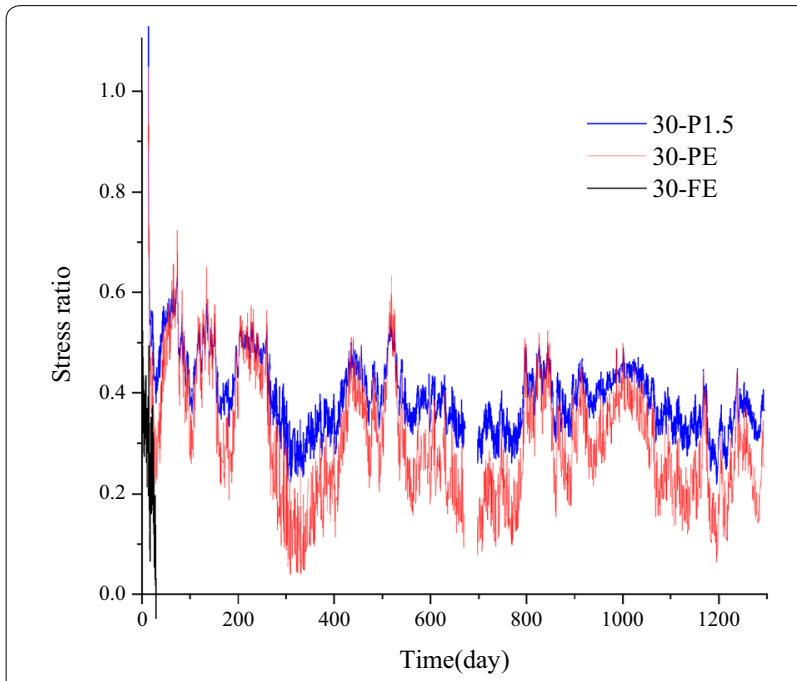

Fig. 5 Comparison of the stress ratios in the different initial stress levels

force can be maintained over a long period of time. In addition, it is difficult to maintain a clamp force over the long term under full compression in the elastic region because the stress of 30-FE decreased to zero at the early stage.

Figure 6 shows a comparison of stress ratios of 30-P1.5, 45-P1.5, 30-P1.6A, B, and 90-P1.6 with different thickness. Materials $30-\mathrm{P} 1.5$ and $45-\mathrm{P} 1.5$ had virtually the same density and the stresses $\sigma_{1 \mathrm{~min}}$ were also quite similar. In addition, the time histories of the stresses were substantially similar, as shown in Fig. 6a, and no difference was found due to the difference in thickness. For specimens 30-P1.6A, B and 90-P1.6, the density was not uniform, and the difference in the stress $\sigma_{1 \text { min }}$ was large, but the stress ratio trends were consistent with one another, as shown in Fig. 6b. Accordingly, the influence of the thickness of the specimen on the stress ratio is small in this test condition.

\section{Effect of the test method and the test period}

The entire period of stress ratios obtained from 20-P2, L45-P2.3 and 30-P1.5, 30-P1.6A, subjected to partial compression in the plastic region is illustrated in Fig. 7 based on the test start date for 20-P2. The test periods were relatively long, over 3 years for 30-P1.5, 4 years for L45-P2.3, and exceeding 5 years for 20-P2. All the specimens showed a tendency to asymptotically approach some value under the influence of humidity fluctuation after the initial rapid stress relaxation.

Using a lag screw in L45-P2.3, a stress ratio of about $50 \%$ was maintained, which was higher than the other specimens. In addition, short-term fluctuations due to changes in humidity were considerably smaller compared with other specimens, despite their lack of moistureproof treatment. These behaviors may be attributed to the uniform shear stress distribution in the axial direction of the threaded portion [20], unlike the bolted joints where the strain concentrates around the washer [16].

With the larger embedded displacement of 20-P2 compared to that of 30-P1.5 and 30-P1.6A, the trend in the stress ratio of 20-P2 was low. Since the influence of the embedded displacement was considered to be small in the plastic region as described in the previous section, the stress ratio may be affected by the extra end distance of the specimen.

Although the tightening date for 30-P1.6 occurred 219 days after the tightening for 30-P1.5, the time history of the stress ratio of 30-P1.6 behaved similarly to 30-P1.5 at 230 days after stressing of 30-P1.6, as shown in Fig. 7. This indicated that the stress reduction appeared to be suppressed approximately 230 days after stressing under this condition. This observation was similar to the finding of Quenneville and Dalen [21] who reported the stress ratios becoming asymptotic to some residual value at approximately 250 days. 


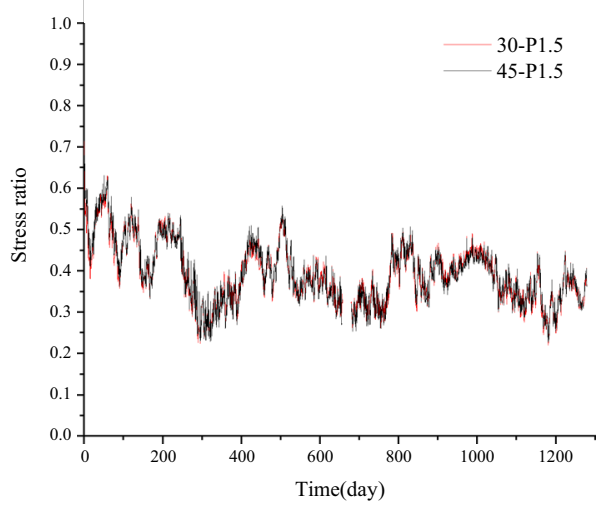

a Embedded displacement $=1.5 \mathrm{~mm}$

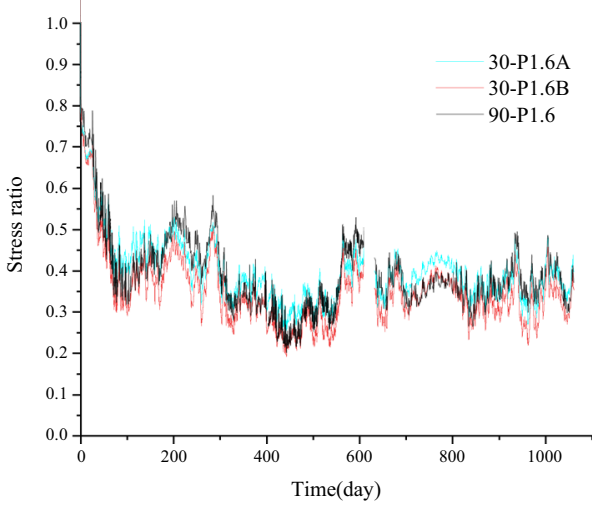

b Embedded displacement $=1.6 \mathrm{~mm}$

Fig. 6 Comparison of stress ratios obtained from the specimens with different thickness in series B

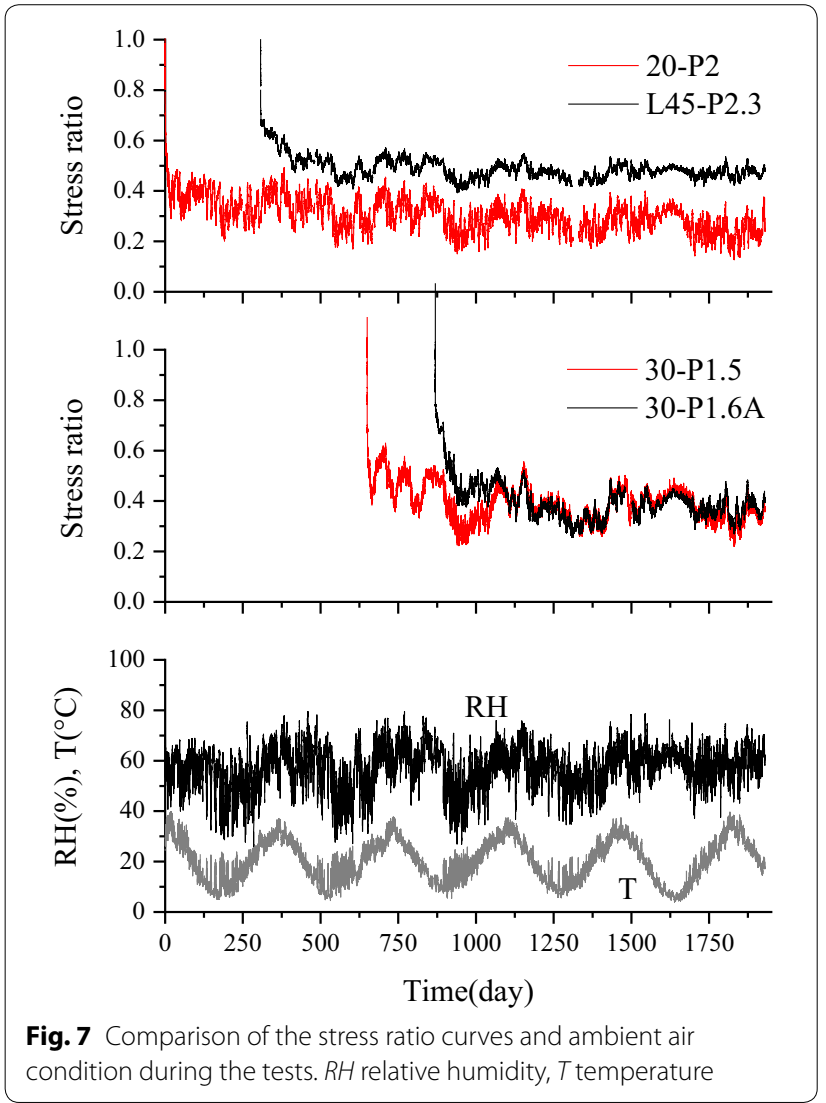

\section{Long-term trend and prediction of residual stress}

Although creep deformation, which is viscoelastic behavior in wood, is often evaluated by the power law [22], Eq. (1) is used to predict creep deflection in Japanese structural design guidelines for wood frame construction [23].

$$
\delta_{1 \min } / \delta_{t}=10^{e} t^{f}
$$

where $\delta_{1 \mathrm{~min}}$ is deformation at time $=1 \mathrm{~min}, \delta_{t}$ is the deformation at time $t, e$ and $f$ are constants. Ohashi et al. [24] reported the creep in I-beams is more accurately predicted with Eq. (1) compared to using the conventional power law. In this study, the stress relaxation is estimated by Eq. (1) by replacing creep deformation with stress. The relationship between the common logarithm of time and the common logarithm of $\sigma_{1 \mathrm{~min}} / \sigma_{t}$ for 30-P1.5 and $30-\mathrm{P} 1.6 \mathrm{~A}$ is shown in Fig. 8 with regression lines. The predicted curves obtained with Eq. (1) are depicted by the dashed curves in Fig. 9 with experimental results for the two specimens. Both predictive curves were consistent with the observed experimental trends.

Table 3 shows the constants for each specimen obtained from the regression and the predicted values $\sigma_{50} / \sigma_{1 \text { min }}$ after 50 years. The predicted stress ratio of $30-\mathrm{PE}$ after 50 years was estimated to be $15 \%$, which is too low to maintain the stress under the assumed humidity fluctuation. On the other hand, except for 30-PE, the predicted ratios were all more than $20 \%$. In particular, the predicted stress ratio of L45-P2.3 was $40 \%$, and the change in stress due to humidity fluctuation was smaller than that of other specimens, which suggests that it is possible to maintain high stress stably.

Figure 10 shows $\sigma_{50} / \sigma_{1}$ min predicted by adding data every half year from 1 min after tightening to verify the influence of the test period. The values go up and down every 6 months. This fluctuation is related to the humidity fluctuation and depends on the season at the beginning of the measurement. For the 20-P2 specimen, which had the longest measurement, the overall predicted trend 


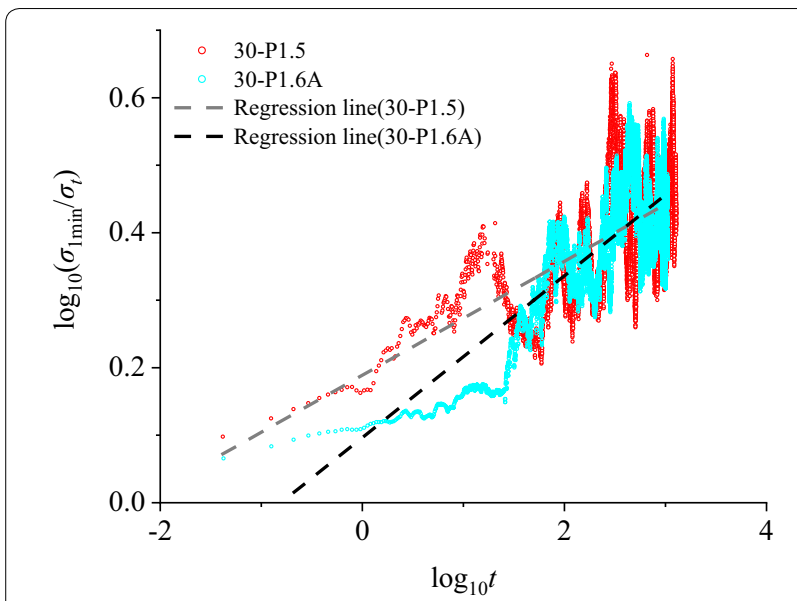

Fig. 8 Typical correlation between $\log _{10} t$ and $\log _{10}\left(\sigma_{1 \mathrm{~min}} / \sigma_{t}\right)$ by Eq. (1) replacing creep deformation with stress

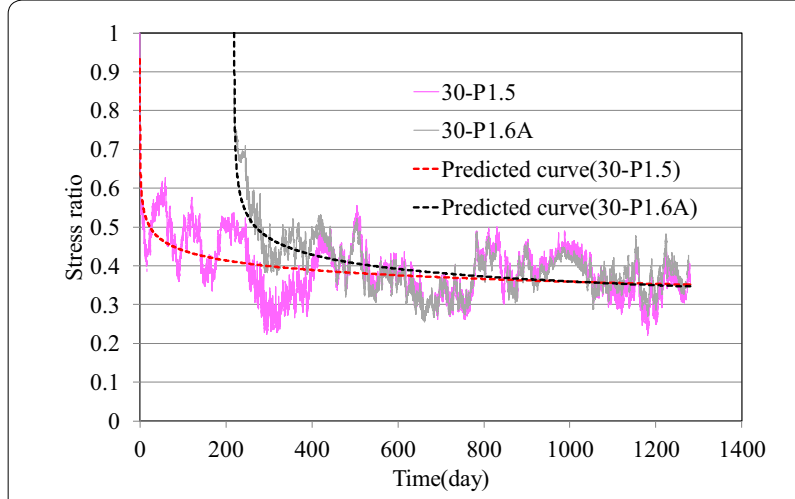

Fig. 9 Stress-relaxation curves and estimated curves by Eq. (1) replacing creep deformation with stress

Table 3 Constants and stress ratio after 50 years estimated by Eq. (1) replacing creep deformation with stress

\begin{tabular}{llll}
\hline Type & $\boldsymbol{f}$ & $\boldsymbol{e}$ & $\boldsymbol{\sigma}_{\mathbf{5 0}} / \boldsymbol{\sigma}_{\mathbf{1} \text { min }}$ \\
\hline 20-P2 & 0.124 & 0.174 & 0.20 \\
30-P1.5 & 0.091 & 0.174 & 0.27 \\
45-P1.5 & 0.098 & 0.155 & 0.27 \\
30-PE & 0.154 & 0.154 & 0.15 \\
30-P1.6A & 0.120 & 0.097 & 0.25 \\
30-P1.6B & 0.126 & 0.143 & 0.21 \\
90-P1.6 & 0.122 & 0.104 & 0.24 \\
L45-P2.3 & 0.057 & 0.155 & 0.40 \\
\hline
\end{tabular}

$e$ and $f$, constants estimated by Eq. (1) replacing creep deformation with stress; $\sigma_{50} / \sigma_{1 \text { min }}$ stress ratio after 50 years decrease, and there a tendency to converge had not yet been observed. The plastic embedded specimens of series B displayed low values at an early stage. However, the decreasing stress trend was not observed after 1 year of measurement; the predicted value increased for longer periods of evaluation.

Such a difference in the tendencies of series A and B is considered to have a large effect of extra end distance of the specimen, as described above.

30-P1.5 and 30-P1.6A showed virtually the same stress ratio after a certain period of time as described in the previous section; however, the predicted value was lower for $30-\mathrm{P} 1.6 \mathrm{~A}$ because the stress relaxation of $30-\mathrm{P} 1.6 \mathrm{~A}$ was suppressed due to the high humidity environment during the first month of measurement, and the slope of the regression line increased, as shown in Fig. 8. Hence, to investigate the long-term performance of wood in an environment where temperature and humidity are not controlled, it is necessary to consider the humidity conditions at the beginning of the test.

\section{Conclusion}

Stress relaxation testing of wood ( $C$. japonica) in the plastic region was conducted over a relatively long period of time. The indoor test environment did not have temperature and humidity control, though it was occasionally heated in winter. The following conclusions were drawn as a result of the tests.

1. The difference in stress ratios due to the difference in the initial clamp force was small in the plastic region, and the higher the initial force, the higher the maintained force. Although the torque imposition time was not considered in the tests for reasons previously stated, the stress relaxation behavior of wood in the plastic region appeared to approach linear viscoelasticity.

2. The clamp force disappeared in the early stage of full elastic compression, and the stress ratio decreases to about 3\% in partial elastic compression. Considering the fluctuation in the clamp force due to changes in humidity, it was difficult to maintain the stress for a long period of time in the elastic region.

3. Since the specimens that were subjected to partial plastic compression at different times showed virtually the same stress ratio after 230 days, the relaxation behavior was suppressed within 1 year under indoor environmental conditions.

4. Plastic clamping using the pull-out reaction force of lag screws resulted in a high stress ratio, and the short-term fluctuation in stress due to humidity fluctuation was small. 

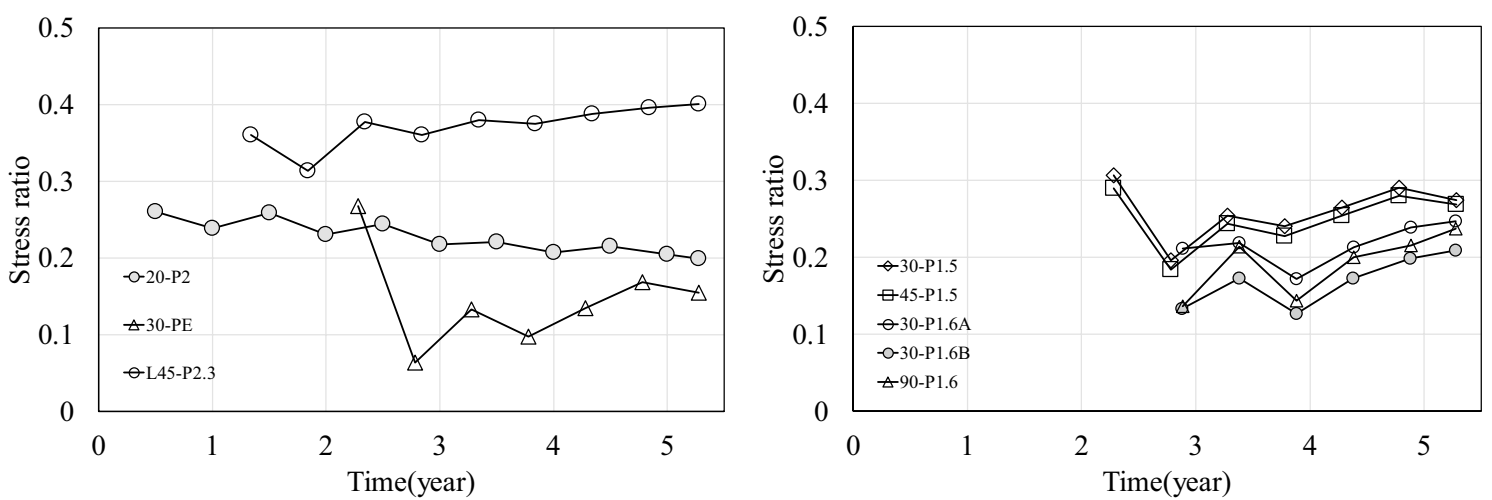

Fig. 10 Stress ratios after 50 years estimated with data from beginning of clamping to every half year. The time axis is based on the test start date of $20-\mathrm{P} 2$

5. The stress ratios after 50 years according to Eq. (1) were $15 \%$ for the elastic region and more than $20 \%$ for the plastic region. When a lag screw was used, the predicted ratio was estimated to be very high (i.e., $40 \%)$.

6. When the stress ratio after 50 years was calculated every 6 months during the measurement period, there was an overall decreasing trend in the predicted values, and there was no tendency to converge for the specimen without sufficient end distance. By contrast, in the specimen with sufficient end distance, the predicted value displayed a tendency to increase over a longer measurement period and appeared to be indicative of the long-term performance.

7. Since a difference was observed in the long-term prediction depending on the humidity environment at the early stage of the tests, it is necessary to consider the start season in tests where the temperature and humidity conditions are not controlled.

\footnotetext{
Abbreviations

$\sigma_{1 \text { min }}$ : stress 1 min after tightening; $\sigma_{50}$ : stress at time $=50$ years; $\sigma_{t}$ : stress at time $t ; \delta_{1 \text { min }}$ : deformation at time $=1 \mathrm{~min} ; \delta_{i}$ : deformation at time $t$.
}

\section{Acknowledgements}

We would like to thank Associate Professor Atsushi Tabuchi of Kyoto Prefecture University for advising on long-term prediction of stress relaxation of wood.

Part of this article was presented at the 67th Annual Meeting of the Japan Wood Research Society, Fukuoka, Japan, March 2017.

\section{Authors' contributions}

YW designed and performed the experiments, analysed the data. HS, AK, DM and $\mathrm{Kl}$ assisted in the preparation of the tests. YW and YF wrote the manuscript in consultation with HS, AK, DM and KI. All authors read and approved the final manuscript.

\section{Funding}

This work was supported in part by the Science and Technology Research Promotion Program for Agriculture, Forestry, Fisheries and Food Industry (27015A).

\section{Availability of data and materials}

Not applicable.

\section{Competing interests}

The authors declare that they have no competing interests.

\section{Author details}

${ }^{1}$ Toyama Prefectural Agricultural Forestry \& Fisheries Research Center, 4940, Imizu, Toyama 939-0311, Japan. ${ }^{2}$ Sugiyama Jogakuen University, 17-3,

Chikusa-ku, Nagoya, Aichi 464-8662, Japan. ${ }^{3}$ Research Institute for Sustainable Humanosphere, Kyoto University, Uji, Kyoto 611-0011, Japan. ${ }^{4}$ Tokyo Metropolitan Industrial Technology Research Institute, 2-4-10, Aomi, Koto-Ku, Tokyo 135-0064, Japan. ${ }^{5}$ University of Fukui, 3-9-1, Fukui, Fukui 910-8507, Japan.

Received: 6 December 2018 Accepted: 10 June 2019 Published online: 19 June 2019

\section{References}

1. Architectural Institute of Japan (2006) Standard for structural design of timber structure (in Japanese). Architectural Institute of Japan, Tokyo, pp 239-247

2. Hirai (1991) Effect of frictional resistance on lateral resistance of bolted timber-joints with steel side-webs (in Japanese). Mokuzai Gakkaishi 37:517-522

3. Awaludin A, Hirai T, Toshiro T, Sasaki Y, Oikawa A (2008) Effects of pretension in bolts on hysteretic responses of moment carrying timber joints. J Wood Sci 54:114-120

4. Awaludin A, Hirai T, Toshiro T, Sasaki Y, Oikawa A (2008) One-year stress relaxation of timber joints assembled with pretensioned bolts. J Wood Sci 54:456-463

5. Wakashima Y, Shimizu H, Ishikawa K, Fujisawa Y (2015) Development of high damping shear walls using wood friction. In: Abstracts of the International symposium on wood science and technology 2015 (IAWPS 2015), Tower Hall Funabori, Tokyo, 15-17 March 2015

6. Wakashima Y, Shimizu H, Fujisawa Y, Ishikawa K, Kitamori A, Matsubara D (2016) High damping shear walls using wood friction joints. In: Proceedings of the world conference on timber engineering 2016, Vienna University of Technology, Vienna, 22-25 August 2016

7. Wakashima Y, Shimizu H, Ishikawa K, Kitamori A, Matsubara D, Fujisawa Y (2018) Evaluation of seismic performance of structure combining wood friction wall and common walls of wooden house. In: Proceedings of 
the world conference on timber engineering 2018, Coex, Seoul, 20-23 August 2018

8. Matsubara D, Shimada K, Nishikawa Y, Nakano T, Hattori N (2014) Relationship between tightening torque and clamp force on bolted joints of timber (in Japanese). Mokuzai Kogyo 69:19-23

9. Matsubara D, Wakashima Y, Fujisawa Y, Shimizu H, Kitamori A, Ishikawa $\mathrm{K}$ (2018) Effects of tightening speed on torque coefficient in lag screw timber joints with steel side plates. J Wood Sci 64:112-118

10. Kitamori A (2009) Study on interlocking timber joint dependent on friction and compression perpendicular to grain of wood (in Japanese). Dissertation, Kyoto University

11. Holzer SM, Loferski JR, Dillard DA (1989) A review of creep in wood: concepts relevant to develop long-term behavior predictions for wood structures. Wood Fiber Sci 21:376-392

12. Schniewind AP (1968) Recent progress in the study of the rheology of wood. Wood Sci Technol 2:188-206

13. Sarisley EF, Accorsi ML (1990) Prestress level in stress-laminated timber bridges. J Struct Eng 116:3003-3019

14. Hisdlop LE (1998) Field performance of timber bridges-15. Pueblo county, colorado, stress-laminated deck bridge. Forest Product Laboratory, Madison

15. Rittere MA, Wacker JP, Duwadi SR (1995) Field performance of stresslaminated timber bridges on low-volume roads. In: Proceedings of the 6th International conference on low-volume roads, Minneapolis, 25-29 June 1995

16. Fujimoto Y, Nishijima T, Mataki Y (1994) Behaviors of production and relaxation of fastening force in bolted joint for wood construction (in Japanese). Sci Bull Facult Agric Kyushu Univ 49:53-60
17. Manrique RE (1969) Stress relaxation of wood at several levels of strain. Wood Sci Technol 3:49-73

18. Kuwamura $\mathrm{H}$ (2012) Technical pitfalls and remedies in stress relaxation test of wood. Study on steel-frame timber structures Part12 (in Japanese). J Struct Constr Eng AlJ 77:937-946

19. Kuwamura $H$ (2012) Anisotropy and densifying effect in bearing stress relaxation of wood. Study on steel-frame timber structures Part13 (in Japanese). J Struct Constr Eng AlJ 77:1429-1436

20. Nakatani M, Komatsu K (2006) Mechanism of pull-out performance in lagscrewbolted timber joints III-Development a theory of pull-out properties perpendicular to the grain (in Japanese). Mokuzai Gakkaishi $52: 160-167$

21. Quenneville P, Dalen KV (1994) Relaxation behaviour of prestressed wood assemblies. Part 1: experimental study. Can J Civ Eng 121:736-743

22. Clouser WS (1959) Creep of small wood beams under constant bending load. Forest Products Laboratory, Madison, p 2150

23. Japan $2 \times 4$ Home Builders Association (2002) Structural design guidelines for wood frame construction (in Japanese). Japan $2 \times 4$ Home Builders Association, Tokyo, pp 219-260

24. Ohashi Y, Matsumoto K, Sato T, Hirai T (2008) Mechanical properties of wooden I-beams with plantation timber materials in hokkaido II. Long term bending creep property (in Japanese). Mokuzai Gakkaishi 54:174-182

\section{Publisher's Note}

Springer Nature remains neutral with regard to jurisdictional claims in published maps and institutional affiliations.

\section{Submit your manuscript to a SpringerOpen ${ }^{\circ}$ journal and benefit from:}

- Convenient online submission

- Rigorous peer review

- Open access: articles freely available online

- High visibility within the field

- Retaining the copyright to your article

Submit your next manuscript at $\boldsymbol{\nabla}$ springeropen.com 